\title{
Article
}

\section{A rapid, chromatography-free route to substituted acridine-isoalloxazine conjugates under microwave irradiation}

Johns, Stephen C., Crouch, Laurie L.E., Grieve, Stephen, Maloney, Holly L., Peczkowski, Gary R., Jones, Allison E., Sharp, Duncan and Smith, Robert B.

Available at http://clok.uclan.ac.uk/13277/

Johns, Stephen C., Crouch, Laurie L.E., Grieve, Stephen, Maloney, Holly L., Peczkowski, Gary R., Jones, Allison E., Sharp, Duncan and Smith, Robert B. ORCID: 0000-0002-2829-5360 (2014) A rapid, chromatography-free route to substituted acridine-isoalloxazine conjugates under microwave irradiation. Tetrahedron Letters, 55 (22). pp. 3308-3311. ISSN 00404039

It is advisable to refer to the publisher's version if you intend to cite from the work. http://dx.doi.org/10.1016/j.tetlet.2014.04.035

For more information about UCLan's research in this area go to

http://www.uclan.ac.uk/researchgroups/ and search for <name of research Group>.

For information about Research generally at UCLan please go to http://www.uclan.ac.uk/research/

All outputs in CLoK are protected by Intellectual Property Rights law, including Copyright law. Copyright, IPR and Moral Rights for the works on this site are retained by the individual authors and/or other copyright owners. Terms and conditions for use of this material are defined in the policies page. 


\title{
A rapid, chromatography free, route to substituted acridine-isoalloxazine conjugates under microwave irradiation
}

\author{
Stephen C. Johns, ${ }^{a}$, Laurie L.E. Crouch, ${ }^{a}$ Stephen Grieve, ${ }^{a}$ Holly L. Maloney, ${ }^{a}$ Gary R. Peczkowski, ${ }^{a}$ Allison E. \\ Jones, ${ }^{a}$ Duncan Sharp ${ }^{b}$ and Robert B. Smitha,*
}

${ }^{a}$ Centre of Materials Science, University of Central Lancashire, Preston, PR1 2HE, UK

${ }^{b}$ Faculty of Health and Social Sciences, Leeds Metropolitan University, LS1 3HE, UK

*Email: rbsmith@uclan.ac.uk,

Tel: +44 (0) 1772894384

\begin{abstract}
Microwave irradiation was applied to a sequence of condensation reactions from readily available 9-chloroacridines to provide a range of novel acridine-isoalloxazine conjugates. The combination of these two moieties, both of biological interest, was achieved by a chromatography free route.

Keywords: Acridine, Isoalloxazine, Flavin, Microwave
\end{abstract}

\section{Graphical Abstract}

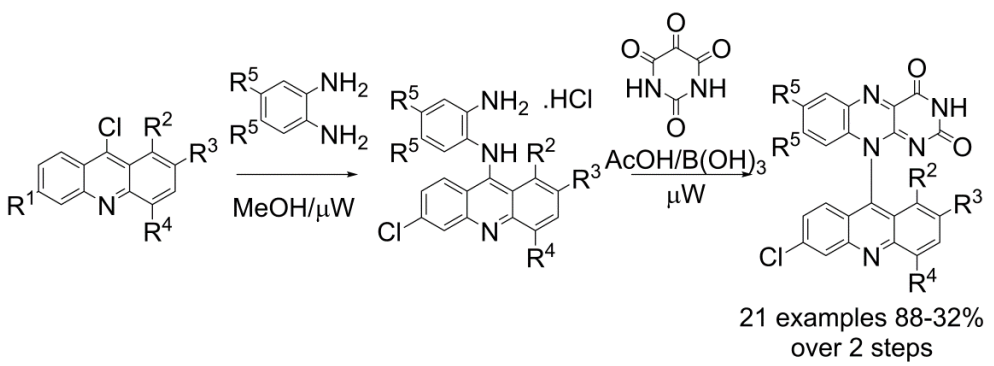

Submitted to

Tetrahedron Letters

Acridine moieties have been of interest to medicinal chemists for many years, often appearing as central scaffolds in many biologically active compounds. ${ }^{1,2,3}$ Indeed acridines exhibit great pharmaceutical importance due to their potent photodynamic biological activities. ${ }^{4}$ However this goes hand-in-hand with its well established toxicity profile ${ }^{5}$ of the molecule itself which represents a considerable obstacle to overcome for progression into main stream healthcare. In contrast, 7,8-dimethyl-10-ribityl isoalloxazine (riboflavin or vitamin B2) is an essential nutrient in humans, and is also a photosensitiser which absorbs in the visible region. It shows impressive activity as both an antibacterial ${ }^{6}$ and antiviral agent through both Type I and Type II photosensitisation. ${ }^{7}$ 
Inspired by the biological activity of both, herein we present a short and efficient method to the rapid generation of hybrid acridine-isoalloxazine conjugates (Figure 1). The isoalloxazine moiety also contains an acidic N-3 proton which may prove useful for attachment of either a solubilising or a targeting moiety. ${ }^{8}$

$<<$ Figure 1>>

Our initial attempts to form the isoalloxazine-acridines followed a three step route from a range of 9-aminoacridines (route A, Scheme 1); firstly condensation with 2-chloronitrobenzenes gave the desired $\mathrm{N}$-substituted 2-nitroaniline in low to moderate yields after chromatography. However, attempted reduction of the nitro group using standard conditions $\left(\mathrm{Zn} / \mathrm{H}^{+}\right)$and subsequent condensation with alloxan monohydrate gave a mixture of products from which the desired compounds could not be isolated. We hypothesised there were three major problems with this route; firstly, the 9-aminoacridines were poor nucleophiles, due to electron withdrawal from the ring nitrogen, resulting in poor yields for the initial $S_{N} A r$ reaction; ${ }^{9}$ secondly, the zinc reduction was not completely selective resulting in numerous by-products; and finally that the intermediates and products were likely to be poorly soluble in most common solvents making column chromatography challenging. ${ }^{10}$ Our second route (route B, Scheme 1) utilised 9chloroacridines as the electrophilic component using the electron withdrawing acridine to our advantage. By using phenylene diamines as the nucleophiles the reduction step was avoided entirely, albeit at the cost of perhaps limiting our isoalloxazines to containing the same group at both the $\mathrm{C} 7$ and $\mathrm{C} 8$ positions. ${ }^{11}$

\section{$<<$ Scheme 1 >>}

In order to optimise the reaction conditions, commercially available 6-chloro-2-methoxyacridine 4a was picked as a model substrate. There have been several reports of 9-chloroacridines reacting with anilines to form substituted $N(9)$ anilinoacridine hydrochloride salts by heating under reflux in methanol. Following the procedure of Plater and coworkers $^{12}$ in methanol under reflux the desired product $\mathbf{6 a}$ was obtained in moderate yield from $\mathbf{4 a}$ (Entry 1, Table 1) with the only purification required being precipitation and filtration. The use of microwave acceleration of organic reactions has found widespread use. ${ }^{13}$ Two of the major advantages of microwave heating are the ability to rapidly heat solvents in sealed tubes past their boiling points, and the uniformity of heating, potentially resulting in fewer byproducts resulting from localised hotspots. ${ }^{14}$ Performing the reaction under conditions of microwave irradiation (110 ${ }^{\circ} \mathrm{C}, 10 \mathrm{~min}$ ) resulted in a much faster and pleasingly a higher yielding reaction (Entry 2, Table 1), although heating the reaction at higher temperature $\left(140{ }^{\circ} \mathrm{C}\right)$ did result in decreased purity. During this work Staderini et al reported a solvent free, microwave route for amination of $\pi$-electron deficient heterocycles including acridines, in their cases the reactions were promoted by the addition of 2 equivalents of phenol, giving excellent yields. ${ }^{15}$ Conventional conditions for condensation of 2-aminoanilines with alloxan monohydrate generally requires prolonged $(\geq 12 \mathrm{~h})$ stirring at room temperature with acetic and boric acid giving moderate to high yields (most often 40-70\%) of isoalloxazines. ${ }^{16}$ In order to increase the rate of this reaction, we again attempted this reaction under microwave irradiation. Condensation of alloxan monohydrate with the acridine salt $6 \mathbf{a}$ in the absence of boric acid even at elevated temperatures $\left(140{ }^{\circ} \mathrm{C}\right)$ did not occur in $\mathrm{MeOH}$ or $\mathrm{AcOH}$ to any measurable extent. The reaction was successful in $\mathrm{AcOH}$ with 1 equivalent of boric acid giving the product 7a in excellent yield $\left(95 \%, 140{ }^{\circ} \mathrm{C}, 10 \mathrm{~min}\right.$, Entry 1, Table 1). Chauhan and coworkers have reported the condensation of some alkyl and aryl substituted 2-aminoanilines with alloxan monohydrate under microwave irradiation in a domestic microwave oven to give 10-substituted isoalloxazines in good yield. ${ }^{17}$ The use of our own conditions gave the product isoalloxazine 7a rapidly in high yield and purity, after precipitation, filtration and washing (including water washes to remove boric acid) without recourse to column chromatography (85\% over 2 steps from $\mathbf{4 a}$ ).

$<<$ Scheme 2>>

Preparation of a range of 9-chloroacridines was performed following reported methods (Scheme 2$)^{18}$ a range of anilines $\mathbf{2}$ were reacted with several 2-chlorobenzoic acids $1{ }^{19}$ The formed crude $N$-aryl anthranillic acids $\mathbf{3}$ were then ring closed with $\mathrm{POCl}_{3}$ under microwave irradiation. ${ }^{20}$ The desired 9-chloroacridines $\mathbf{4}$ could be isolated by a variety of methods, vacuum sublimation, vacuum filtration through a pad of silica gel or recrystallisation to give single compounds. Several greener methods have been reported in the literature for the synthesis of $N$-aryl anthranillic acids including solvent free conditions with microwave irradiation ${ }^{21}$ and use of ultrasound in aqueous solution. ${ }^{22}$ 
The optimised conditions were applied to a range of acridines derived from 2,4-dichlorobenzoic acid 4a-g (Scheme 3, Table 1). Several different phenylene diamines 5a-c were used to vary the electronics of the isoalloxazine system and to make flavin derivatives, giving the corresponding products 6, 6' or 6" in moderate to high yields as the corresponding hydrochloride salts. ${ }^{23}$ The lowest yield was obtained from 2,4-dimethoxyacridine 4c, which has the most electron rich C9 position (69\% entry 6 , Table 1 ). In all cases the reaction was highly regioselective with no evidence of any reaction with the 6-chloro group. Formation of the isoalloxazines 7, 7', 7', gave the desired products in all cases, ${ }^{24}$ however in several cases the final compounds were contaminated with quantities of byproducts often from residual phenylene diamines present in the intermediate hydrochloride salts. Attempted purification of several products that were of unacceptable purity by column chromatography or recrystallization was particularly difficult due to the insolubility of the acridine-isoalloxazines 7. It was discovered that the majority of impurities could be removed by high temperature extraction/recrytalization in methanol under microwave irradiation (see supplementary information) and the purified yields are reported in parentheses. Extraction in a sealed system at high temperature is both faster, uses a much smaller volume of solvent than traditional methods such as soxhlet extraction and is often used in the extraction of organic molecules from environmental ${ }^{25}$ or cellular matrices. ${ }^{26}$ As, in this case, the products are sparingly soluble in methanol the use of lower volumes of solvent results in less product being lost. With the 1,4dimethoxy substituted intermediate 6d" $1 \mathrm{H}$ NMR of the product 7d" after precipitation contained residual starting material, which was also successfully removed by the microwave extraction. We suggest that the increased steric hindrance in this case (and presumably to a lesser extent in the case of $\mathbf{6 d}$ ) resulted in slower conversion and the reaction would benefit from a prolonged reaction time. Scale-up $(4 \times)$ of the reactions to form $7 \mathbf{a}$ and $7 \mathbf{a}$ ' gave the desired products in similar yields although it should be noted that stirring of the reaction mixture must be efficient ensure complete conversion of starting material.

$<<$ Scheme 3 and Table 1>>

Similar reactions were attempted with acridines derived from 2-chlorobenzoic acid $\mathbf{4 h}-\mathbf{l}$ and 2-chloro-4-nitrobenzoic acid 4m-n (Scheme 4, Table 2). With substrate $\mathbf{4 h}$, which was particularly deactivated by the 2-methoxy group, only a moderate yield of acridine salt $\mathbf{6 h}$ was encountered reacting with $o$-phenylene diamine 5a $(67 \%)$, however extending the reaction time to $20 \mathrm{~min}$ increased the yield to be comparable with the others (86\%, Entry 3, Table 2). Substrate 41 had the opposite problem, activation by the 4-nitro group made the substrate too reactive, and the reaction produced a complex mixture of products as a black tar (Entry 10, Table 2). Indeed nucleophilic displacement on 9-chloro-4nitroacridine $4 \mathbf{l}$ has been reported in the literature only once with an aniline electrophile and in this case was performed at $0{ }^{\circ} \mathrm{C} .{ }^{27}$ Pleasingly 6-nitro substituted acridines (where the nitro group does not withdraw electrons from the 9- position by resonance) did not suffer from this problem giving the desired products (6m and 6n, Entries 11-12, Table 2). Conversion to the acridine-isoalloxazines gave the products 7 , in most cases without further purification being required, and where this was not the case high temperature microwave extraction was performed to remove unwanted impurities. The products containing 6-nitrosubstituted acridines 7m-n were particularly insoluble in acetic acid and crystallised out in the reaction vessel as a $\sim 1: 1$ mixture with acetic acid (by $1 \mathrm{H} \mathrm{NMR}$ ) and were isolated as such.

$<<$ Scheme 4 and Table 2>>

$<<$ Scheme 5>>

The use of substrate 4o, containing an extra contiguous ring proved challenging (Scheme 5), and the normal optimised conditions failed to give any product, whilst raising the temperature significantly resulted in the formation of several by-products; in this case a slower $1 \mathrm{~h}$ reaction at a slightly elevated temperature $\left(120^{\circ} \mathrm{C}\right)$ gave the best compromise between rate and purity. The isoalloxazine 70 was formed from the $\mathrm{HCl}$ salt $\mathbf{6 0}$ using the optimised conditions. In this case two purifications, including chromatography and a high temperature microwave extraction, were required to give the product in high purity and the significantly lower yield can be attributed to this.

The products were characterised initially by $1 \mathrm{H}$ NMR and exhibited some interesting features. Signal broadening was often observed in the protons between the two tricylic systems. Steric clashes along these sides will prevent the molecules from adopting a planar structure. The two ring systems must be offset with rotation around the N10-C9' bond being restricted, resulting in the products existing as two enantiomeric atropisomers. Separation of axially chiral $\mathrm{N}$-phenyl isoalloxazines has been reported, ${ }^{28}$ and planar chiral flavin derivatives have been used as asymmetric 
catalysts in sulfide ${ }^{29}$ and Baeyer-Villiger ${ }^{30}$ oxidations. The twist in the structure will also result in decreased conjugation between the two ring systems. In the case of product $\mathbf{7 d}$ one of the acridine methoxy groups points directly towards the isoalloxazine ring system, and the chemical shift of the methyl group is particularly low (3.23 ppm in 7d compared to $4.03 \mathrm{ppm}$ in $\mathbf{6 d}$ ); the shielding in this case is due to the magnetic anisotropy of the isoalloxazine system.

In summary, we report a rapid, chromatography free, method for the preparation of acridine-isoalloxazine conjugates from substituted 9-chloroacridines. We are currently undertaking biological and photophysical testing of the compounds to determine their applicability for photodynamic antimicrobial chemotherapy.

We are pleased to acknowledge the financial support from the Centre for Materials Sciences, School of Forensic and Investigative Sciences and the EPSRC national mass spectrometry service centre (NMSSC), Swansea for the recording of HRMS.

Supplementary data (experimental procedures and analytical data for the compounds 6a-o and 7a-o) associated with this article can be found in the online version XXXXXXX XXXXXX 
${ }^{1}$ Liao, S.-R.; Zhou, C.-X.; Wu, W.-B.; Ou, T.-M.; Tan, J.-H.; Li, D.; Gu, L.-Q.; Huang, Z.-S. Eur. J. Med. Chem. $2012,53,52$.

${ }^{2}$ Malachowska-Ugarte, M.; Cholewinski, G.; Dzierzbicka, K.; Trzonkowski, P. Eur. J. Med. Chem. 2012, $54,197$.

${ }^{3}$ Luan, X.; Gao, C.; Zhang, N.; Chen, Y.; Sun, Q.; Tan, C.; Liu, H.; Jin, Y.; Jiang, Y. Bioorg. \& Med. Chem. $2011,19,3312$.

${ }^{4}$ Wainwright, M. J. Antimicrob. Chemother. 2001, 47, 1.

${ }^{5}$ Ferguson, L. R.; Denny, W. A. Mutation Res./Rev. In Genetic Toxicology 1991, 258, 123.

${ }^{6}$ Makdoumi, K.; Bäckman, A.; Mortensen, J.; Crafoord, S. Graefe's Archive for Clinical and Experimental Ophthalmology 2010, $248,207$.

${ }^{7}$ Ruane, P. H.; Edrich, R.; Gampp, D.; Keil, S. D.; Leonard, R. L.; Goodrich, R. P. Transfusion 2004, 44, 877.

${ }^{8}$ Dutra, J. K.; Cuello, A. O.; Rotello, V. M. Tetrahedron Lett. 1997, 38, 4003.

${ }^{9} 9$-Aminoacridines have been used successfully in this reaction with 2-halonitrobenzenes for the preparation of several $N(9)$ anilinoacridines in good yield, however in most cases chromatographic purification was required after $12 \mathrm{~h}$ heating with $\mathrm{Cs}_{2} \mathrm{CO}_{3} / \mathrm{DMF}$ : Gellerman, G.; Gaisin, V.; Brider, T. Tetrahedron Lett. 2010, 51, 836.

${ }^{10}$ Farrán, Á.; Claramunt, R.; López, C.; Pinilla, E.; Torres, R.; Elguero, J. Arkivoc 2007, 20.

${ }^{11}$ Stevens and co-workers substituted 9-chloroacridines with several 4-substituted $o$-phenylene diamines and in the majority of cases the reaction was highly regioselective where the substituent exerted a strong electronic effect: Hagan, D. J.; Giménez-Arnau, E.; Schwalbe, C. H.; Stevens, M. F. G. J. Chem. Soc., Perkin Trans. 1 1997, 2739.

${ }^{12}$ Plater, M. J.; Greig, I.; Helfrich, M. H.; Ralston, S. H. J. Chem. Soc., Perkin Trans. $12001,2553$.

${ }^{13}$ Caddick, S.; Fitzmaurice, R. Tetrahedron 2009, 65, 3325

${ }^{14}$ Lidström, P.; Tierney, J.; Wathey, B.; Westman, J. Tetrahedron 2001, 57, 9225.

${ }^{15}$ Staderini, M.; Cabezas, N.; Bolognesi, M. L.; Menéndez, J. C. Tetrahedron 2013, 69, 1024.

${ }^{16}$ Choy, N.; Russell, K. C.; Alvarez, J. C.; Fider, A. Tetrahedron Lett. 2000, 41, 1515.

${ }^{17}$ Chauhan, S. M. S.; Singh, R.; Geetanjali Synth. Comm. 2003, 33, 1179.

${ }^{18}$ Crouch, L. L. E.; Grieve, S.; Maloney, H. L.; Peczkowski, G. R. Unpublished results.

${ }^{19}$ Litchfield, V. J.; Smith, R. B.; Franklin, A. M.; Davis, J. Synth. Commun. 2008, 38, 3447.

${ }^{20}$ Taherpour, A. A; Kvaskoffa, D.; Bernhardta, P. V.; Wentrup, C. J. Phys. Org. Chem. 2010, $23,382$.

${ }^{21}$ Martína, A.; Mesaa, M.; Docampoa, M. L.; Gómeza, V.; Pellóna, R. F. Synth. Commun. 2006, 36, 271.

${ }^{22}$ Palaciosa, M. L. D.; Comdoma, R. F. P. Synth. Commun. 2003, 33, 1771.

${ }^{23}$ For example: A mixture of 6,9-dichloro-2-methoxyacridine $4 \mathbf{a}$ ( $278 \mathrm{mg}, 1.0 \mathrm{mmol}, 1$ equiv) and phenylenediamine 5a (238 mg, $2.2 \mathrm{mmol}$, 2.2 equiv) was suspended in $\mathrm{MeOH}(5 \mathrm{~mL})$ and subjected to microwave irradiation $\left(110{ }^{\circ} \mathrm{C}, 10 \mathrm{~min}\right)$. The reaction mixture was allowed to cool to room temperature giving a red liquid with a red/orange precipitate. The mixture was then transferred into rapidly stirred Et ${ }_{2} \mathrm{O}$. After stirring for $5 \mathrm{~min}$, the solid was isolated by vacuum filtration, washed with $\mathrm{Et}_{2} \mathrm{O}$ and dried giving the product hydrochloride salt $6 \mathbf{6}$ ( 359 mg, $93 \%$ ) as a red/orange solid.

${ }^{24}$ For example: A mixture of diamine intermediate 6a $(193 \mathrm{mg}, 0.50 \mathrm{mmol}, 1.0$ equiv), alloxan monohydrate (96.0 mg, $0.60 \mathrm{mmol}, 1.2$ equiv) and boric acid (30.9 mg, $0.50 \mathrm{mmol}, 1.0$ equiv) were suspended in $\mathrm{AcOH}(5 \mathrm{~mL})$ and subjected to microwave irradiation (140 ${ }^{\circ} \mathrm{C}, 10$ $\mathrm{min}$ ). The reaction mixture was allowed to cool to room temperature forming a yellow/orange precipitate. The mixture was then transferred into rapidly stirred $\mathrm{Et}_{2} \mathrm{O}$. After stirring for $5 \mathrm{~min}$ the solid was isolated by vacuum filtration, washed $\mathrm{Et}_{2} \mathrm{O}$ and $\mathrm{H}_{2} \mathrm{O}$ and dried giving the product isoalloxazine-acridine conjugate $7 \mathbf{a}(217 \mathrm{mg}, 95 \%)$ as a yellow solid.

${ }^{25}$ Letellier, M.; Budzinski, H. Analusis 1999, 27, 259.

${ }^{26}$ Chan, C.-H.; Yusoffa, R.; Ngoh, G.-C.; Kung, F. W.-L. J. Chromatogr. A 2011, 1218, 6213.

${ }^{27}$ Su, T.-L.; Chen, C.-H.; Huang, L.-F.; Chen, C.-H.; Basu, M. K.; Zhang, X.-G.; Chou, T.-C. J. Med. Chem. 1999, $42,4741$.

${ }^{28}$ Shinkai, S.; Nakao, H.; Kuwahara, I.; Miyamoto, M.; Yamaguchi, T.; Manabe, O. J. Chem. Soc., Perkin Trans. $1,1988,313$.

${ }^{29}$ Shinkai, S.; Yamaguchi, T.; Manabe, O.; Toda, F. J. Chem. Soc, Chem. Commun., 1988, 1399.

${ }^{30}$ Murahashi, S.; Ono, S.; Imada, Y. Angew. Chem. Int. Ed. 2002, 41, 2366.

Table 1- Synthesis of acridine-isoalloxazines 7a-g and intermediate diaryl amines 6a-g derived from 6,9dichloroacridines 4a-g

\begin{tabular}{|c|c|c|c|c|c|c|c|}
\hline Entry & $\begin{array}{l}\text { Starting } \\
\text { material }\end{array}$ & $\overline{\mathrm{R}^{2}}$ & $\mathrm{R}^{3}$ & $\mathrm{R}^{4}$ & $\mathrm{R}^{5}$ & Yield $\mathbf{6}^{\mathbf{a}}$ & Yield $7^{\mathbf{b}}$ \\
\hline 1 & $4 \mathbf{a}$ & $\mathrm{H}$ & $\mathrm{OMe}$ & $\mathrm{H}$ & $\mathrm{H}$ & $\mathbf{6 a}: 53 \%^{c}$ & \\
\hline 2 & $4 a$ & $\mathrm{H}$ & $\mathrm{OMe}$ & $\mathrm{H}$ & $\mathrm{H}$ & 6a:93\% & 7a:95\% \\
\hline 3 & $4 a$ & $\mathrm{H}$ & $\mathrm{OMe}$ & $\mathrm{H}$ & $\mathrm{Me}$ & 6a':91\% & 7a':86\% \\
\hline 4 & $4 a$ & $\mathrm{H}$ & $\mathrm{OMe}$ & $\mathrm{H}$ & $\mathrm{Cl}$ & 6a":90\% & 7a'":92\% \\
\hline 5 & $4 b$ & $\mathrm{H}$ & $\mathrm{H}$ & $\mathrm{OMe}$ & $\mathrm{H}$ & $\mathbf{6 b}: 83 \%$ & $7 \mathbf{b}:(76 \%)^{\mathrm{d}}$ \\
\hline 6 & $4 c$ & $\mathrm{H}$ & $\mathrm{OMe}$ & $\mathrm{OMe}$ & $\mathrm{H}$ & 6c: $69 \%$ & $7 \mathbf{c}:(68 \%)^{\mathrm{d}}$ \\
\hline 7 & $4 d$ & $\mathrm{OMe}$ & $\mathrm{H}$ & $\mathrm{OMe}$ & $\mathrm{H}$ & 6d:83\% & $7 \mathbf{d}:(84 \%)^{\mathrm{d}}$ \\
\hline 8 & $4 d$ & $\mathrm{OMe}$ & $\mathrm{H}$ & $\mathrm{OMe}$ & $\mathrm{Cl}$ & 6d"::84\% & 7d": $:(38 \%)^{\mathrm{d}}$ \\
\hline 9 & $4 e$ & $\mathrm{H}$ & $\mathrm{Me}$ & $\mathrm{H}$ & $\mathrm{H}$ & 6e:95\% & 7e:86\% \\
\hline 10 & $4 f$ & $\mathrm{H}$ & $\mathrm{H}$ & $\mathrm{Me}$ & $\mathrm{H}$ & 6f: $96 \%$ & 7f:(61\%) $)^{\mathrm{d}}$ \\
\hline 11 & $4 \mathrm{~g}$ & $\mathrm{H}$ & $\mathrm{H}$ & $\mathrm{H}$ & $\mathrm{H}$ & 6g:82\% & 7g:83\% \\
\hline
\end{tabular}

${ }^{\mathrm{a}}$ Isolated yields after precipitation into $\mathrm{Et}_{2} \mathrm{O}$, filtration, washing and drying, $1 \mathrm{mmol} \mathrm{scale}$; ${ }^{\mathrm{b}}$ Isolated yields after precipitation into $\mathrm{Et}_{2} \mathrm{O}$, filtration, washing and drying, $0.5 \mathrm{mmol} \mathrm{scale}{ }^{\mathrm{c}}$ Heating under reflux $1.5 \mathrm{~h}$; ${ }^{\mathrm{d}}$ Pro rata after microwave extraction/recrystallization of a $150 \mathrm{mg}$ portion (see supplementary information). 
Table 2- Synthesis of acridine-isoalloxazines 7h-n and intermediate diaryl amines $\mathbf{6 h - n}$ derived from 9dichloroacridines 4 h-n without a 6-chloro group

\begin{tabular}{|c|c|c|c|c|c|c|c|}
\hline Entry & $\begin{array}{l}\text { Starting } \\
\text { material }\end{array}$ & $\mathrm{R}^{1}$ & $\mathrm{R}^{3}$ & $\mathrm{R}^{4}$ & $\mathrm{R}^{5}$ & Yield $\mathbf{6}^{\mathbf{a}}$ & Yield $\mathbf{7}^{\mathbf{b}}$ \\
\hline 1 & $4 h$ & $\mathrm{H}$ & $\mathrm{OMe}$ & $\mathrm{H}$ & $\mathrm{H}$ & 6h:85\% & 7h:73\% \\
\hline 2 & $4 h$ & $\mathrm{H}$ & $\mathrm{OMe}$ & $\mathrm{H}$ & $\mathrm{Me}$ & 6h':97\% & $7 h^{\prime}: 77 \%$ \\
\hline 3 & $4 i$ & $\mathrm{H}$ & $\mathrm{H}$ & $\mathrm{OMe}$ & $\mathrm{H}$ & $\mathbf{6 i}: 86 \%{ }^{\mathrm{c}}$ & $7 \mathbf{i}:(64 \%)^{\mathrm{d}}$ \\
\hline 4 & $4 \mathbf{i}$ & $\mathrm{H}$ & $\mathrm{H}$ & $\mathrm{OMe}$ & $\mathrm{Me}$ & $\mathbf{6 i}: 93 \%{ }^{\mathrm{e}}$ & $7 \mathbf{i}^{\prime}: 73 \%$ \\
\hline 5 & $4 i$ & $\mathrm{H}$ & $\mathrm{H}$ & $\mathrm{OMe}$ & $\mathrm{Cl}$ & $\mathbf{6 i} "=: 82 \%$ & $7 \mathbf{i} ":: 82 \%$ \\
\hline 6 & $4 j$ & $\mathrm{H}$ & $\mathrm{Me}$ & $\mathrm{H}$ & $\mathrm{H}$ & $\mathbf{6 j}: 83 \%$ & 7j:70\% \\
\hline 7 & $4 k$ & $\mathrm{H}$ & $\mathrm{H}$ & $\mathrm{H}$ & $\mathrm{H}$ & 6k:97\% & 7k: $88 \%$ \\
\hline 8 & $4 k$ & $\mathrm{H}$ & $\mathrm{H}$ & $\mathrm{H}$ & $\mathrm{Me}$ & 6k':85\% & $7 \mathbf{k}^{\prime}: 89 \%$ \\
\hline 9 & $4 \mathbf{k}$ & $\mathrm{H}$ & $\mathrm{H}$ & $\mathrm{H}$ & $\mathrm{Cl}$ & 6k'":87\% & $7 \mathbf{k} " 9: 94 \%$ \\
\hline 10 & 41 & $\mathrm{H}$ & $\mathrm{H}$ & $\mathrm{NO}_{2}$ & $\mathrm{H}$ & - & - \\
\hline 11 & $4 m$ & $\mathrm{NO}_{2}$ & $\mathrm{OMe}$ & $\mathrm{H}$ & $\mathrm{H}$ & 6m:86\% & $\mathbf{7 m}: 79 \%$ \\
\hline 12 & $4 n$ & $\mathrm{NO}_{2}$ & $\mathrm{Me}$ & $\mathrm{H}$ & $\mathrm{H}$ & 6n:90\% & $7 \mathbf{n}: 76 \%{ }^{\mathrm{f}}$ \\
\hline
\end{tabular}

${ }^{\mathrm{a}}$ Isolated yields after precipitation into $\mathrm{Et}_{2} \mathrm{O}$, filtration, washing and drying, $1 \mathrm{mmol}$ scale; ${ }^{\mathrm{b}}$ Isolated yields after precipitation into $\mathrm{Et}_{2} \mathrm{O}$, filtration, washing and drying, $0.5 \mathrm{mmol}$ scale ${ }^{\mathrm{c}}$ After heating for $20 \mathrm{~min}$, $(67 \%$ with only 10 min heating); ${ }^{\mathrm{d}}$ Pro rata after microwave extraction/recrystallization of a $150 \mathrm{mg}$ portion (see supplementary information); ${ }^{\mathrm{e}}$ After 20 min heating; ${ }^{\mathrm{f}}$ Isolated as an $\sim 1: 1$ mixture with $\mathrm{AcOH}$.

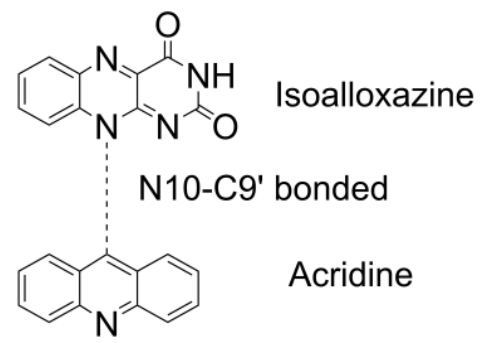

Figure 1- Structures of isoalloxazine and acridine

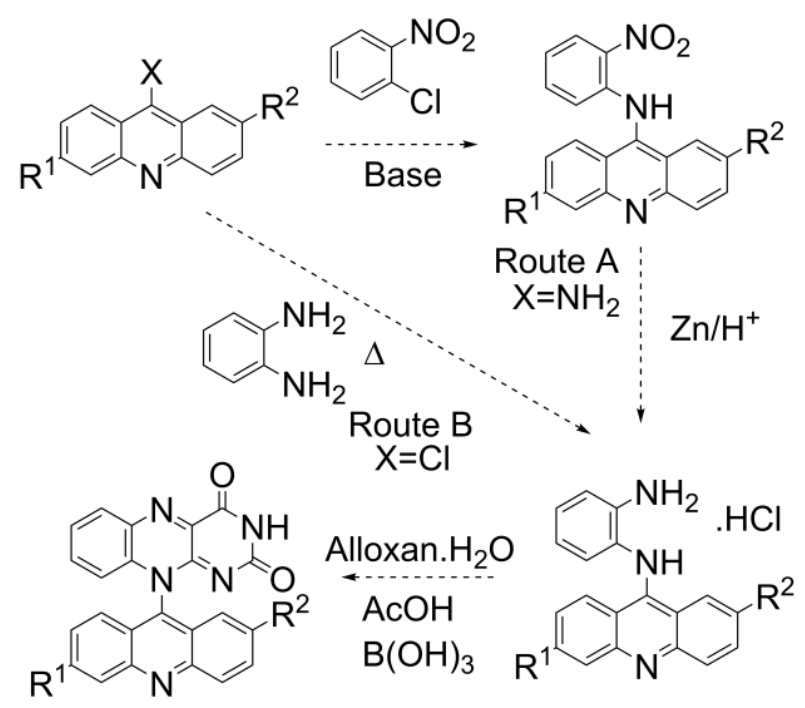

Scheme 1- Routes to isoalloxazine-acridine conjugates. Route A previously attempted 3 step route. Route B new 2 step route. 
<smiles>[R]c1cc([R])c(Nc2ccc(C(=O)O)c(Nc3cc([R])c([R])cc3[R])c2)cc1[R]</smiles>

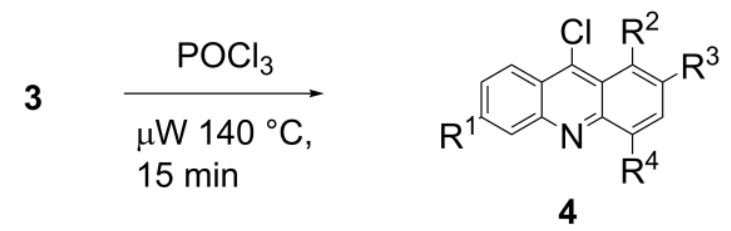

Scheme 2- Preparation of the 9-chloroacridine 4 starting materials<smiles>[R]c1cc([R])c2nc3cc(Cl)ccc3c(Cl)c2c1[R]</smiles>

4<smiles>[R][R]1cc(N)c(N)cc1N</smiles><smiles>COC(=O)OC</smiles><smiles>[R][R]1cc(N)c(N)cc1[R]</smiles><smiles>[R]CCNc1c2ccc(Cl)cc2nc2c([R4])cc([R])c([R])c12</smiles>

$$
\begin{aligned}
& 6 \mathrm{R}^{5}=\mathrm{H} \\
& \text { 6' }^{5}=\mathrm{Me} \\
& \text { 6" }^{\prime} \mathrm{R}^{5}=\mathrm{Cl}
\end{aligned}
$$<smiles>O=C1NC(=O)C(=O)NC1=O</smiles>

\section{$\mathrm{AcOH} / \mathrm{B}(\mathrm{OH})_{3}$} $\mu \mathrm{W} 140{ }^{\circ} \mathrm{C}$,

$10 \mathrm{~min}$

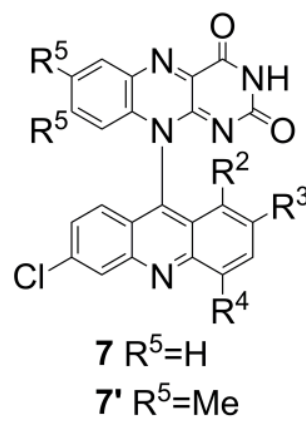

7" $\mathrm{R}^{5}=\mathrm{Cl}$

Scheme 3- Microwave route to acridine-isoalloxazines 7a-g from 6,9-dichloroacridines<smiles>[R][R]c1ccc2c(Cl)c3cc([R])cc([R])c3nc2c1</smiles>

4<smiles>[R]c1cc(N)c(N)cc1N</smiles><smiles>[R][R]c1ccc(Nc2c3cc([R])cc([R4])c3nc3cc([R])cc(N)c23)c(N)c1</smiles>

$6 \mathrm{R}^{5}=\mathrm{H}$

6' $\mathrm{R}^{5}=\mathrm{Me}$ 6" $\mathrm{R}^{5}=\mathrm{Cl}$<smiles>O=C1NC(=O)C(=O)C(=O)N1</smiles>

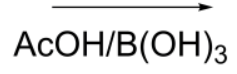
$\mu \mathrm{W} 140^{\circ} \mathrm{C}$, $10 \mathrm{~min}$

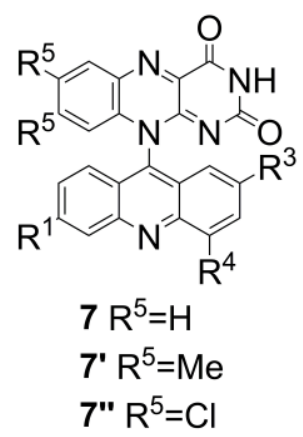


Scheme 4- Microwave route to acridine-isoalloxazines 7h-n from 6-hydro or nitro 9-chloroacridines $\mathbf{4 h - n}$<smiles>Clc1ccc2c(Cl)c3ccc4ccccc4nc-3c2c1</smiles><smiles>Nc1ccccc1N</smiles>

$\mathrm{MeOH}, \mu \mathrm{W}$

$120^{\circ} \mathrm{C}, 1 \mathrm{~h}$

40<smiles></smiles>

60

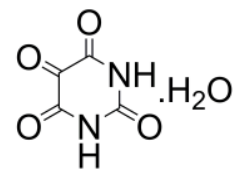

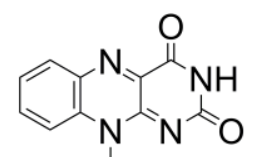

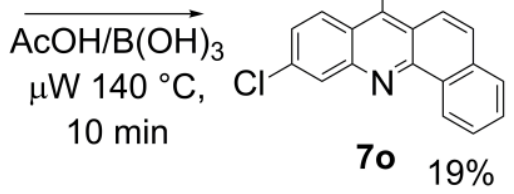

Scheme 5- Extension of the method to form an isoalloxazine conjugate of a 3,4-benzacridine. 